\title{
Dental Students' Motivations for Their Career Choice: An International Investigative Report
}

\author{
Jonathan Du Toit, B.Ch.D.; Sameer Jain, B.D.S.; Victor Montalli, D.D.S., M.Sc.; \\ Urvashnee Govender, B.O.H., M.P.H.
}

Abstract: This study's aim was to investigate on an international scale the reasons why individuals are currently choosing dentistry as a career. An observational, descriptive, cross-sectional study was conducted on a cohort of first-year dental students from thirteen countries on six continents in 2011-12 ( $\mathrm{n}=711$ ). Participants completed the Du Toit Questionnaire for Health Workers and Students, designed for this study, to disclose the reason(s) why they chose a career in dentistry. Data collected from the questionnaire were analyzed in EpiInfo version 7.1.1.14. The response rate was 89.1 percent; the respondents' average age was nineteen years; and their gender was 54 percent female and 46 percent male. The motive selected by the highest percentage (37.4 percent) was "Dentists have enough time off for family life." The second most popular motive at 36.3 percent was "I want to be a dentist who helps poor and underprivileged people." A strong relationship was found between this altruistic motive and students' having been accepted into their program by means of a personal interview or motivational essay as one of the admissions criteria $\left(\mathrm{p}<0.05, \mathrm{r}^{2}=0.89\right)$. This study found that the two strongest motivations for these students from around the world to seek a dental career were the flexible work schedule, leaving time for family life, and the opportunity to help those less fortunate. Dental school admissions policies that provide for review of applicants' motivations may produce dentists with stronger altruistic interest in the profession.

Dr. Du Toit is a dentist, Faculty of Dentistry and WHO Oral Health Collaborating Centre, University of the Western Cape, South Africa; Dr. Jain is a dentist, MGV's KBH Dental College \& Hospital, Maharashtra University of Health Sciences, Nashik, India; Dr. Montalli is an oral pathologist, São Leopoldo Mandic Institute and Research Center, Campinas, São Paulo, Brazil; and Dr. Govender is an oral hygiene lecturer, Griffith University, School of Dentistry and Oral Health, Gold Coast Campus, Australia. Direct correspondence and requests for reprints to Dr. Jonathan Du Toit, Faculty of Dentistry and WHO Oral Health Collaborating Centre, University of the Western Cape, Private Bag X17, 7535, South Africa; jondutoit@uwc.ac.za.

Keywords: dental education, dental students, dental school admissions, altruism, career motivations

Submitted for publication 3/17/13; accepted 6/14/13

$\mathrm{T}$ The World Health Organization places emphasis on developing global policies in oral health care, ${ }^{1,2}$ thus encouraging international collaboration and consistency. Meeting these goals requires some worldwide congruency among academic institutions that educate oral health practitioners, and one of the interests all share is the need to select from a large pool of applicants those students who will best fulfil the institution's mission and contribute to their profession over the course of their careers. The motivations of aspiring dentists have been a subject of study for more than twenty years, across seventeen countries. ${ }^{3-24}$ However, the majority of this research has been carried out in a single country, with only two studies reporting on career motivations in more than one country. ${ }^{8,14}$ To date, only a single investigation has taken a multinational perspective, and it covered only three countries..$^{14}$ Overall, dental students' motives have been previously analyzed by gender, age, race, comparison of predoctoral and postdoctoral levels, contribution to the knowledge of policy makers and workforce planners in terms of workforce retention, demographic distribution, and identification of factors affecting the long-term contribution of oral health care practitioners. ${ }^{9,12,21-24}$

A recurrent dental career motivation reported in the literature is altruism, an expected factor since dentistry is a healing science. Karibe et al.'s research in Japan and Sweden reported that altruism was dental students' primary motivation, ${ }^{8}$ as did Al-Bitar et al. for Jordanian dental students, Khami et al. for Iranian dental students, and Brand et al. for Australian dental students. ${ }^{11,12,22}$ Prestige/social image and financial reward have been other prominent recurring motivations reported for Iranian, Indian, Tunisian, Jordanian, South African, Syrian, British, U.S., Nigerian, and Australian dental students. ${ }^{3,9,11-13,15-17,20,22}$ Our review of the literature identified the desire to help others, prestige, job security, and financial reward as the primary career motives for dental students around the world (Table 1). These findings are often correlated with career aspirations and expectations after graduation. ${ }^{4-7,9,10,12,13}$ Irrelevant motives have been de-emphasized, and pertinent motives 
Table 1. Overview of motivations for students entering dentistry found in previous studies

\begin{tabular}{|c|c|c|}
\hline Country of Study & Primary Motivations Found in Study & First Author, Year \\
\hline India & Job security, financial benefit, work independence & Aggarwal, 2012 \\
\hline Syria & Means to achieve personal goals, employment abroad & Mashlah, 2012 \\
\hline Iran & Work independence, social factors & Vahid Dastjerdi, 2012 \\
\hline Iran & General interest in medicine, prestige & Baharvand, 2011 \\
\hline Brazil & Job conception & Freire, 2011 \\
\hline Japan & Family expectations & Karibe, 2009 \\
\hline Sweden & Altruism & Karibe, 2009 \\
\hline South Africa & Job security & Lalloo, 2008 \\
\hline United States & Inspired by family dentist & Hawley, 2008 \\
\hline Jordan & Prestige, altruism & Al-Bitar, 2008 \\
\hline Iran & Altruism, intellectual challenge, social status, job security & Khami, 2008 \\
\hline United Kingdom & $\begin{array}{l}\text { Good quality of life, professional status, financial benefit, job security, } \\
\text { flexibility }\end{array}$ & Gallagher, 2008 \\
\hline Japan, Canada, Thailand & Interpersonal motives, altruism, academic interest & Karibe, 2007 \\
\hline Nigeria & Family influence, interest, prestige, employment & Orenuga, 2006 \\
\hline United States & Financial benefit, altruism, flexibility & Scarbecz, 2002 \\
\hline United Kingdom & Status, job security, regular hours, independence & Crossley, 2002 \\
\hline Tunisia & Prestige, job security & Maatouk, 2001 \\
\hline Ireland & Ease of employment, self-employment, regular hours & Hallissey, 2000 \\
\hline Australia & Altruism, independence, job satisfaction, financial security & Brand, 1996 \\
\hline South Africa & Image of the profession to achieve personal goals & Chikte, 1992 \\
\hline
\end{tabular}

ranked..$^{9,22}$ One study analyzed the objectivity of the term "career motives" and sought to classify the motives, ${ }^{23}$ while another study assessed the relevance of career motives to dental school admissions. ${ }^{21}$ Consistently, however, national results have differed, and the relevance of admissions policy to dental career motives has been little explored. The data are dense, and correlations are complex. To date, there has been no research regarding career motivations conducted with an international cohort of students spanning many continents. A better understanding of these motivations may be relevant to the selection and training of dentists. ${ }^{21}$

If international congruency is sought in terms of oral health care objectives and oral health practitioners are the ones who will help achieve those objectives, then should not these practitioners' motives be aligned with the principles of academic dental institutions? The aim of this study was to survey dental students from thirteen countries to determine their career motivations and assess whether admission methods are conducive to selecting these types of students. The study also aimed to confirm the motives previously reported in the literature: altruism, social image, and financial reward. Our null hypothesis was that motives may differ internation- ally and that correlation may exist between dental schools' admission requirements and the motives of dental students.

\section{Methods}

An observational, descriptive, cross-sectional study was conducted on a cohort of first-year dental students from thirteen countries on six continents. Self-administered questionnaires were given to a convenience sample of dental students attending one dental school in each of the following countries: South Africa, Australia, United Kingdom, United States, Brazil, India, Thailand, Taiwan, Japan, Singapore, Italy, Turkey, and Russia ( $\mathrm{n}=798)$. Only first-year students were invited to participate, so as to isolate what we hypothesized to be authentic and undeveloped attitudes toward their future careers. It could be argued that attitudes evolve as students progress year by year through a dental program, and we wanted to limit confounding variables. Bias and a developed opinion were further avoided by not including repeating first-year students (an exclusion criterion). No exception was made with regards to race, gender, or age. Older first-year students holding a prior degree, as well as those who did not, were 
included since an opinion of their future dental career should have been at an equal development stage as their younger colleagues. Exclusion criteria also disallowed the participation of any students in their second year of study or later.

Collection of data took place during 2011 and 2012 since a single academic year at some dental schools extends from one year into the next. A senior student or member of the staff at the participating dental school who was familiar with research and questionnaire administration acted as research coordinator and collaborated in the data collection. These coordinators were responsible for explaining the study purpose and the questionnaire instructions and for obtaining the students' informed consent. The participants were informed of their rights with regards to data collection and were free to volunteer consent prior to participation in the study. The participants' personally identifying information was not and will not be disclosed in any publication, to any staff member of participating dental schools, or to anyone other than the authors. The questionnaire did not identify students by name. An ethics senate at the University of the Western Cape's Faculty of Dentistry and WHO Collaborating Oral Health Centre reviewed and approved the protocol for this study (ethics registration number 11/5/24). The research proposal was then reviewed and approved at the participating institutions prior to data collection.

Students volunteered their opinion with regards to their motivation(s) for pursuing a career in dentistry. The instrument listed fifty possible motives for entering the dental profession in the form of personal statements with which respondents could agree. The guidelines instructed participants to read through the list of fifty options prior to answering and to do so without consulting a neighbor so as to limit social desirability bias. ${ }^{25}$ The Gallagher et al. questionnaire ${ }^{13}$ was used, modified in wording and design based on input from a multinational focus group of senior dental students acting as research coordinators. The motive statements drew on previously published motive inquiries from the literature and were modified to accommodate international students: they were simple and straightforward, easy to translate in countries where needed, and easy for a population of current students to readily understand. The use of formal text and ambiguous language was specifically avoided in this questionnaire, which was henceforth called the Du Toit Questionnaire Instrument for Health Workers and Students (www.drmiles .co.za/questionnaire).
The participating students were instructed to choose a minimum of one motive from the list and as many as they felt were relevant. The instructions stipulated that if a student selected more than one motive, a primary or main motive should be identified with the number 1 . Provision for the response "other" was also made. The completed questionnaires were collected by the coordinators in each country and sent to the study authors for analysis. Results were compiled in a Microsoft Excel version 2013 data sheet and sorted by country and gender. Mean values for age and gender were calculated per country and internationally as a whole. We agreed that sorting and reporting on data by race were not relevant. ${ }^{26}$

The coordinators at the dental schools supplied the following information about each's institution: length of dental training program (years), admission test or exam required (yes/no), motivational essay required (yes/no), and admissions interview required (yes/no). These data were processed by the Centers for Disease Control and Prevention's EpiInfo version 7.1.1.14 program (www.cdc.gov/epiinfo/) to determine any statistically relevant deductions. Descriptive analysis of the results was carried out, and 95 percent confidence intervals were calculated for mean values of motivations per country as well as internationally. The association between admissions evaluations and altruistic motive was determined by linear regression test and Pearson's correlation coefficient. Using a 5 percent significance level, we tested the null hypothesis that a correlation existed among this international cohort of dental students, their motives for choosing dentistry as a career, and the admissions evaluations they underwent at their respective dental schools.

\section{Results}

Of the questionnaires distributed to 798 firstyear dental students, 711 were completed satisfactorily (response rate 89.1 percent). Eighty-seven students did not respond or did not fully complete the questionnaire (omitting age, gender, etc.). The age of the respondents ranged from seventeen to thirty-four years, with a mean age for all thirteen countries of nineteen years. The wide variation is due to some dental schools, as in the United States, requiring a college degree prior to the dental program; this practice results in an older student population in comparison to countries like South Africa and India, which enroll dental students directly after high 
school. Overall, females ( 54 percent) exceeded males (46 percent). The gender weighting differed widely by country-ranging from 89 percent male in the UK to 70 percent female in both South Africa and Russia (Figure 1).

Although students could select one or several reasons from fifty options for why they chose to pursue dentistry (indicating the main motive with the number 1), all the responses selected were tallied and weighted. The results are presented in two parts: part one reports the number one motive named by country, and part two reports the collective, international ranking. The primary motive selected for pursuing dentistry in Australia, South Africa, United States, Taiwan, and Singapore was "Dentists have enough time off for family life." No other single first choice motive compared in terms of statistical significance. The first ranked main or first choice motives selected by country are shown in Table 2 . Of the total responses internationally, two motives emerged most often: "Dentists have enough time off for family life" (37.4 percent) and "I want to be a dentist who helps poor and underprivileged people ... improve their oral health" (36.3 percent). The latter motive was the only altruistic motive available from the list of fifty options. Figures 2, 3, and 4 show a ranking of the weighted motives (percentages) selected by respondents in all thirteen countries collectively.

A simple linear regression analysis showed a relationship between dental schools' admissions methods and the altruistic inclination among their first-year dental students. At 95 percent confidence interval, a correlation was found between participants selecting the altruistic motive and being a student at a school that used some form of motive evaluation in its admission criteria $(p=0.041)$. Students from countries whose dental schools did not include an essay or one-on-one interview in its admission practices were the respondents who selected the altruistic motive the least (Figure 5). Of the students who selected the altruistic motive, 78 percent were attending dental schools that evaluated applicants by means of motivational essay or personal interview. With the exception of Brazil, all schools in this study that did not evaluate applicants' motivations for choosing a dental career as part of their admission policies had respondents with weaker altruistic motives. In the linear regression analyses, a statistically significant relationship $(\mathrm{p}=0.058)$ was found for the predictor "no admissions policy: motivational essay or interview" and selection of the altruistic motive "I want to be a dentist who helps poor and underprivileged

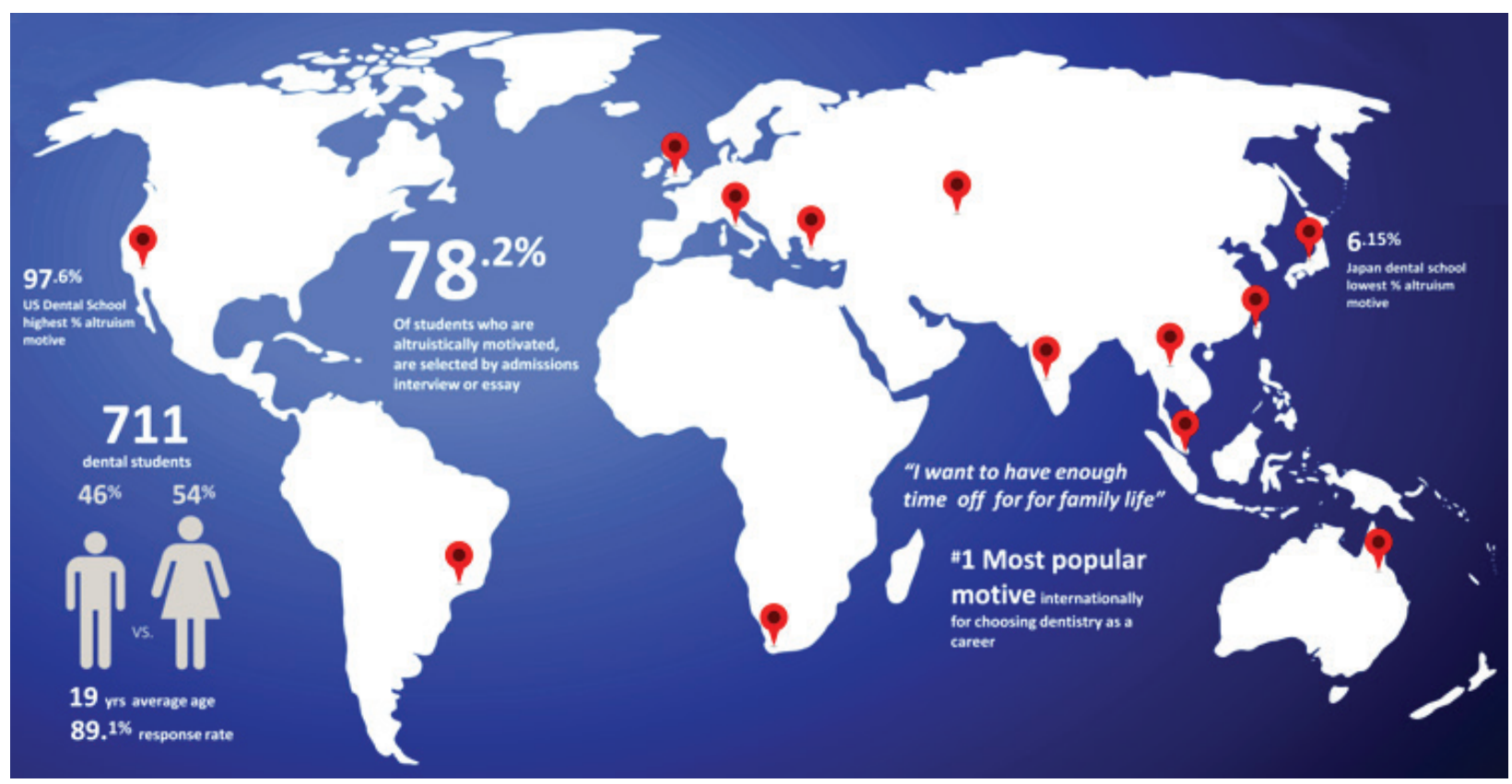

Figure 1. Geographic representation of study population with summarized results 


\section{Table 2. First choice motivations by country compared to motivations cited most often}

\begin{tabular}{lll} 
Country & First Choice Motivations Cited Most Often & Most Popular Motivations Most Often Cited \\
\hline $\begin{array}{l}\text { United Kingdom } \\
\text { United States }\end{array}$ & $\begin{array}{l}\text { My dentist inspired me. } \\
\text { Thailand }\end{array}$ & Dentists have enough time off for family. \\
$\begin{array}{l}\text { Taiwan } \\
\text { Singapore }\end{array}$ & Dentists have enough time off for family. & I want to help the poor and underprivileged. \\
Brazil & Dentists have enough time off for family. & Dentists have enough time off for family. \\
& Dentistry is really interesting. & I want to help the poor and underprivileged. \\
Japan & My parents wanted me to do dentistry. & I want to help the poor and underprivileged. \\
Russia & My parents wanted me to do dentistry. & Dentists have enough time off for family. (tie) \\
Italy & Dentistry is really interesting. & There are variety of opportunities in dentistry. \\
Turkey & For the money. Dentists earn a lot. & My parents wanted me to do dentistry. \\
India & I wanted to study medicine instead. & My parents wanted me to do dentistry. \\
South Africa & Dentists have enough time off for family. & For the money. Dentists earn a lot. \\
Australia & Dentists have enough time off for family. & I want to be in charge of the dental team.
\end{tabular}

Note: See Figures 2 and 3 for full wording of each motivation statement.

people ... to improve their oral health" as the continuous variable. Pearson's correlation coefficient also indicated a strong positive linear relationship between these $(r=0.89)$.

\section{Discussion}

This is the first study to systematically examine why current dental students are choosing to enter the profession on a truly multinational, multicontinental basis. It is also the first study to attempt to examine the relationship between dental students' motivations and dental schools' admissions policies.

The first choice motive selected by respondents in the majority of the countries (Table 2) and the motive most often selected by all the countries (Figure 2 ) were the same: "Dentists have enough time off for family life." It is notable that, of the 266 participants who selected this motive, 198 were female. This is also not surprising since female students exceeded male students in the sample as a whole: females exceeded males in eight of the thirteen countries, by as much as a two-thirds majority in three of the countries. Many females' interest in having both work and family life may help explain this trend. ${ }^{27,28}$

A near tie for the next most popular motive selected in all thirteen countries was the only altruistic option on the questionnaire: "I want to be a dentist who helps poor and underprivileged people . . . to improve their oral health." This finding is also not surprising since dentistry is a vocation in the healing sciences, and the desire to treat and care for patients is a foundation principle of the profession. ${ }^{29}$ There are, however, ongoing discussions as to what exactly is meant by altruism. Depending on the definition, one could argue that teaching, conducting clinical research (for the benefit of others), being concerned about the oral health of one's community, and being concerned with a poor community's access to care all share elements of altruism. The term usually refers to the principle and practice of selfless concern and devotion to others. ${ }^{30}$ We view the second most popular motive selected by dental students as closely related to this definition.

As the third most popular motive, 30.1 percent of the respondents overall selected "Dentists are guaranteed jobs." In North America, according to labor statistics on employment opportunities, ${ }^{31,32}$ this belief is well supported, as is the motivation selected by 20 percent of the respondents that "Dentists earn a lot of money." However, these positive aspects of being a dentist may not hold true in all job markets around the world. Even though the Russian dental students selected "Dentists earn a lot of money" as their first motive, labor statistics in that country report the contrary. ${ }^{33}$ Any misconceptions students have about the ease of getting a job and the income it produces will likely result in disappointment and lack of satisfaction in one's career choice after entering practice.

The dental schools in South Africa, Australia, Brazil, Japan, Italy, Turkey, and India included in this study base their assessment of an applicant's qualifications solely on academic ability, without evaluating his or her attitude about becoming a 


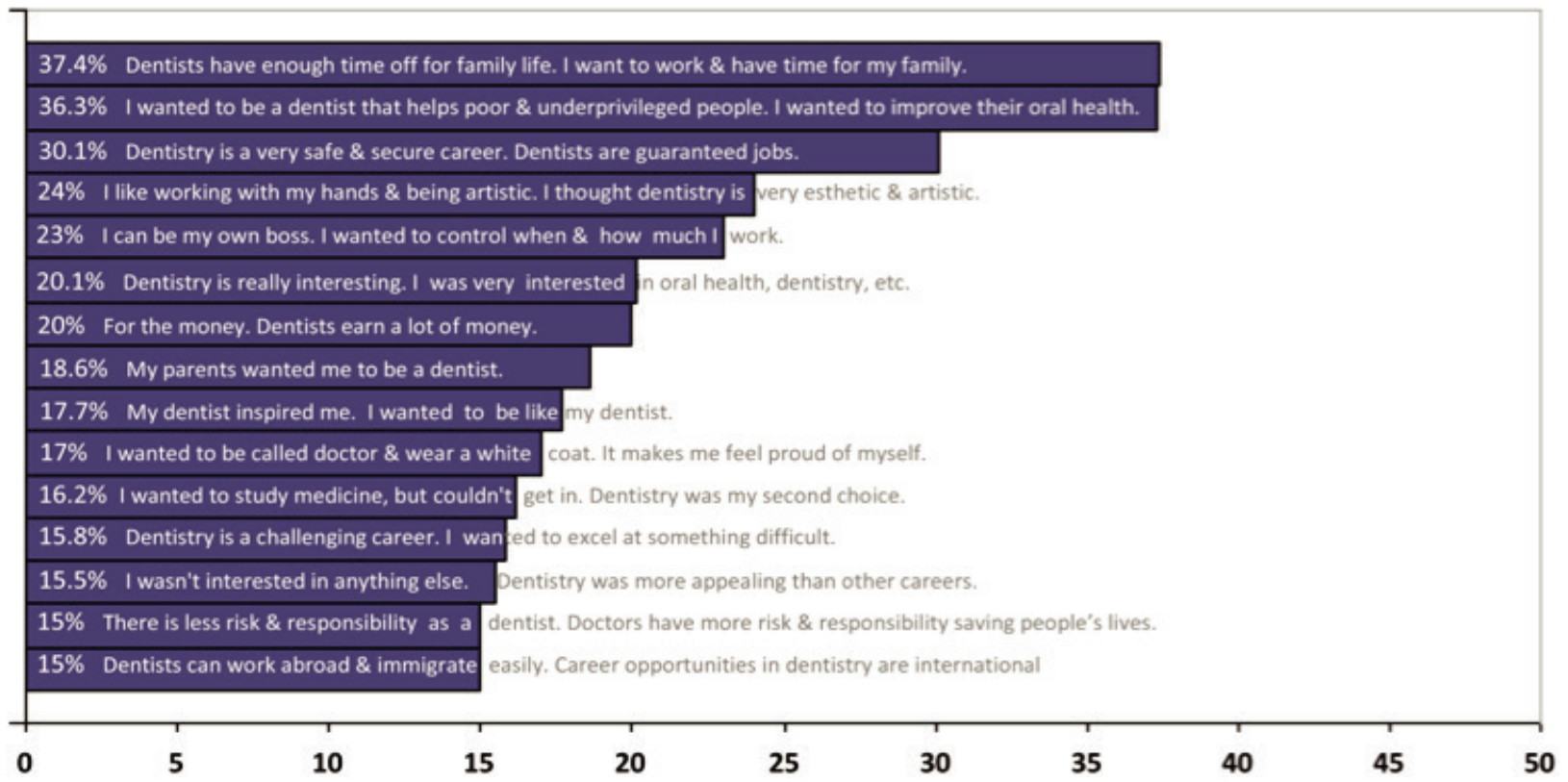

Figure 2. The most popular motivations $(\geq 15 \%)$ selected by students from all countries in study

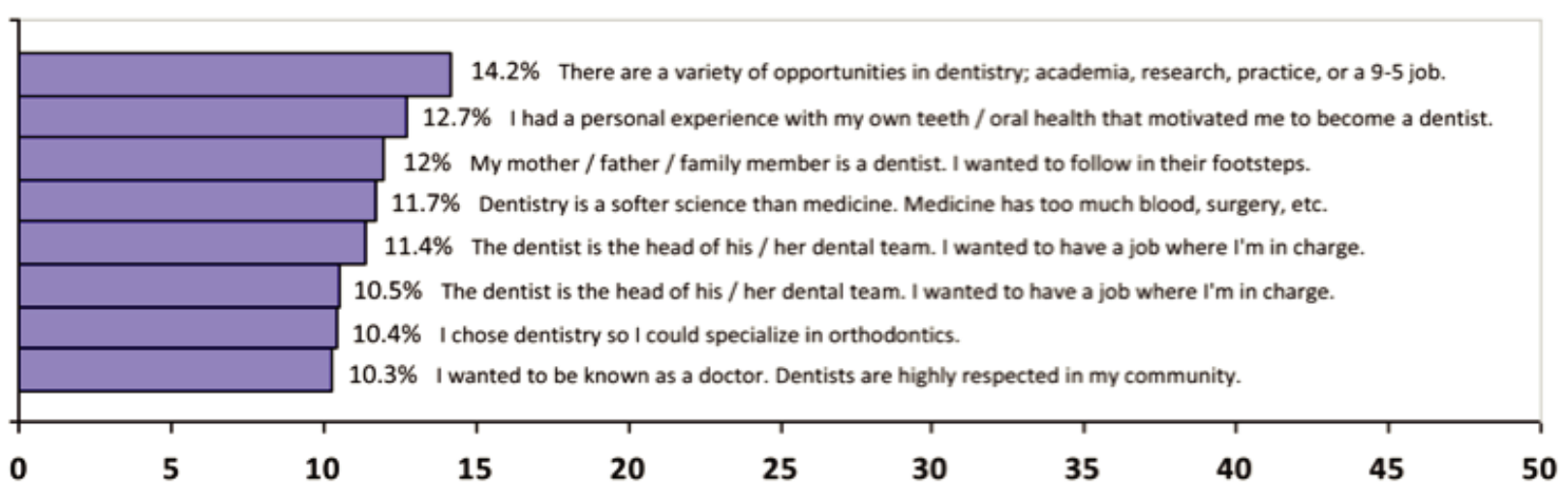

Figure 3. The next most popular motivations (10-14.2\%) selected by students from all countries in study

health care provider. Students at these dental schools are admitted based on school leaving results or by an admissions examination, and an admissions interview, questionnaire, or motivational essay is not required. The assumption could be made that access to the profession is thus granted by some dental schools to academically skilled individuals without making provision for evaluation of their career mo- tives. Admissions methods vary among countries and schools, but the results of our study suggest that admissions methods that evaluate motivations could help dental schools better understand an applicant's interest in the profession, altruistic or otherwise, and use that information to help them select students who will meet the wide range of requirements for being a successful practitioner. 


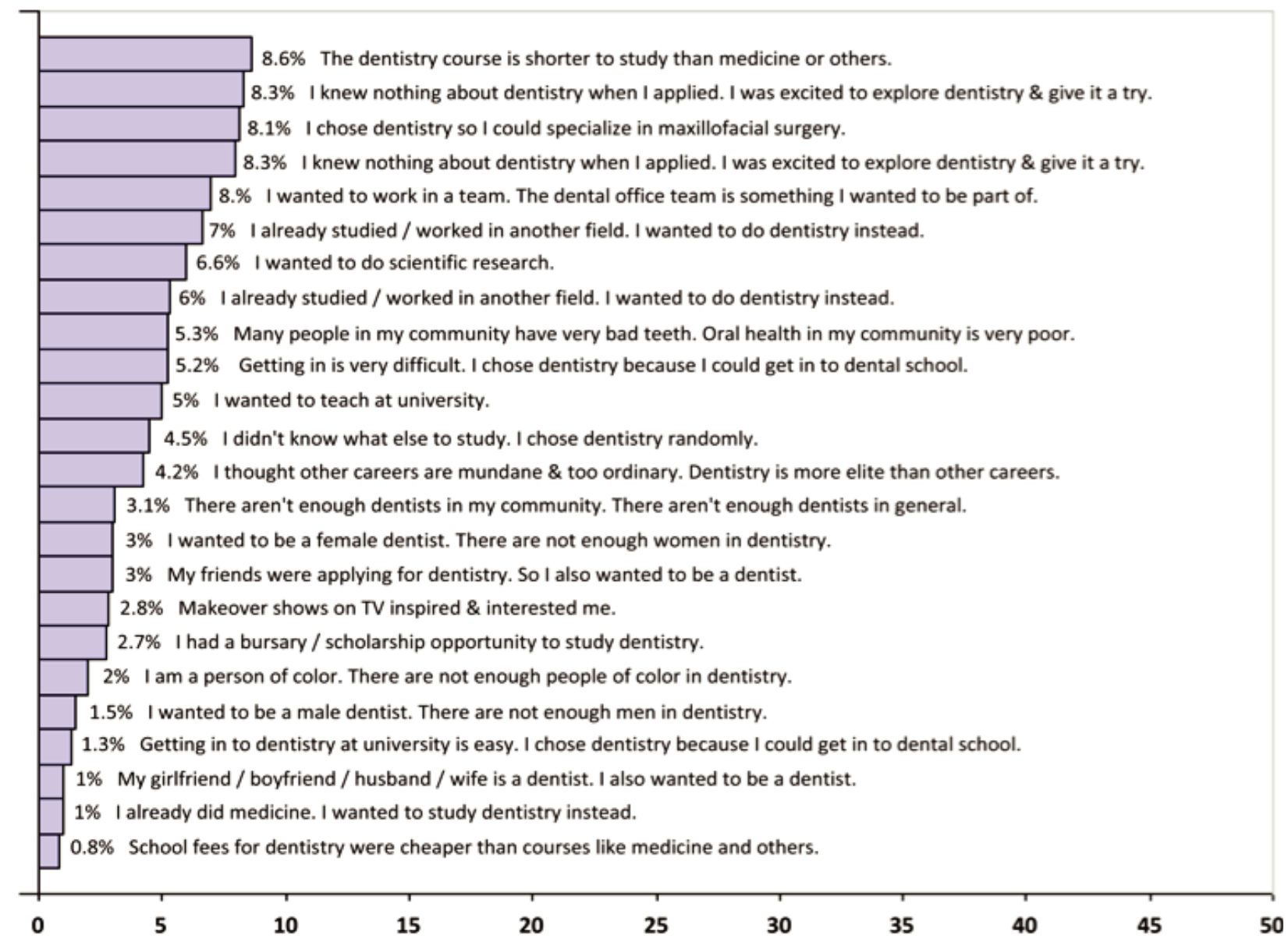

Figure 4 . The least popular motivations $(<10 \%)$ selected by students from all countries in study

\section{Limitations}

This was an international study, carried out in thirteen countries, but it was conducted at a single dental school in each country. It would be incorrect to assume that a single dental school represents the entire dental student population of that country. The appropriate ratio of participants per country was a significant challenge we faced since some of the participating countries had many more dental schools than others. For consistency, we decided to include only a single school for each country. This selection of schools by convenience could have had a significant impact on the results of this study and our interpretation. For example, dental schools in the United States vary widely in the focus they place on various aspects of education and practice: most public schools must meet state or regional requirements, others are community service-oriented, while others have a strong commitment to research. While we acknowledge these differences, we also appreciate the value of gaining a picture of international dentistry as a whole, especially with WHO's interest in worldwide consistency in oral health principles.

Another limitation is based on the fact that some dental schools had first-year student cohorts far larger than others, making interpreting findings across the differently sized groups difficult. Also, ensuring uniformity among the research coordinators in each country could not absolutely be ensured. It cannot be guaranteed that each managed the data collection at his or her dental school identically.

Finally, desirability bias among these young adults answering the questionnaires in the company of their peers could have influenced the outcomes 


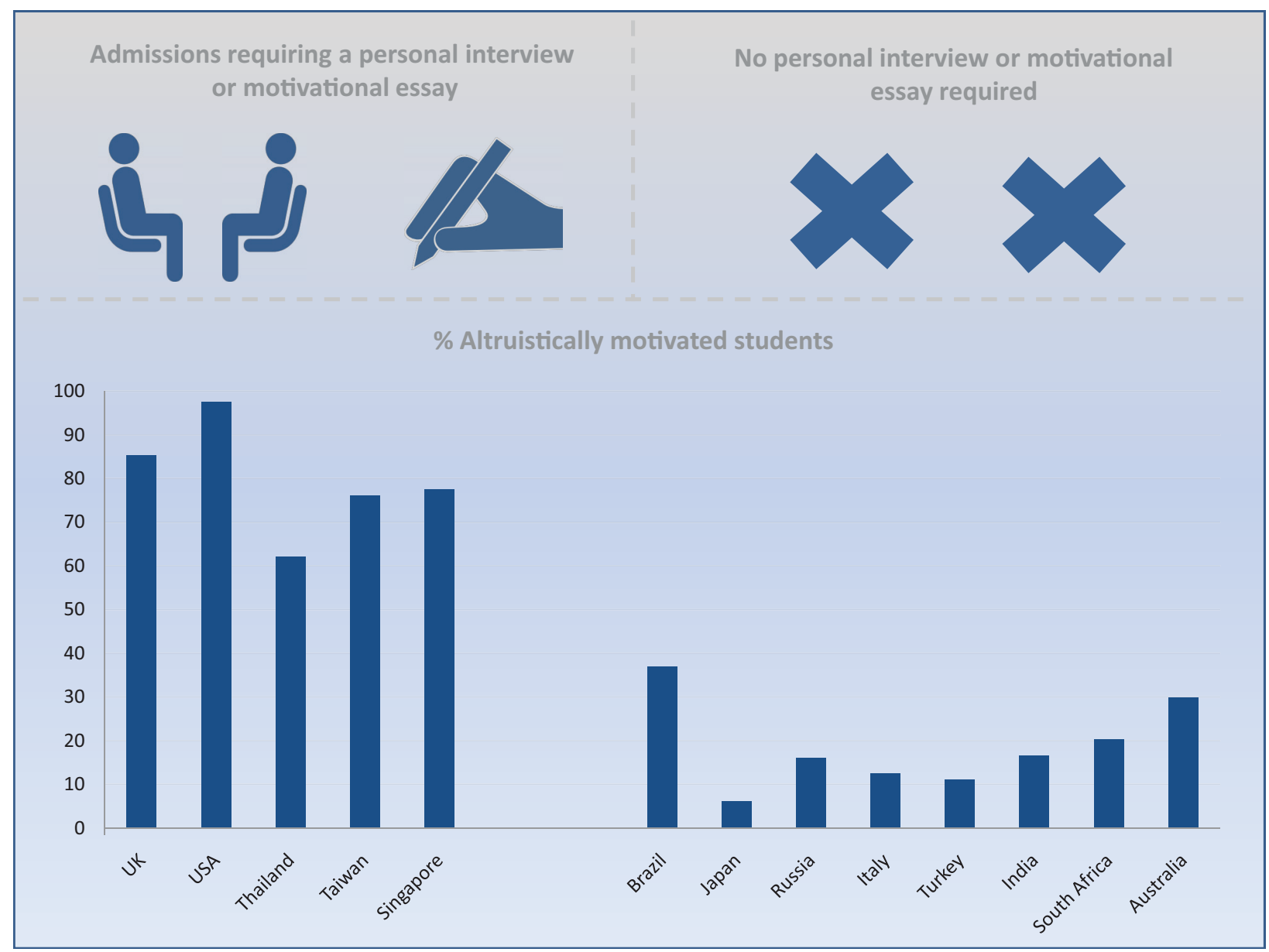

Figure 5. Comparative illustration of altruistically motivated students (\%) from dental schools evaluating motivations during admissions process and those not

of the study. The questionnaire instructions were an attempt to circumvent that possibility.

\section{Conclusion}

This study found that these first-year dental students' motivations for choosing a career in dentistry were consistent among some countries and differed among others. One of the most important findings is that a correlation existed between dental schools' admission methods and the students' reasons for choosing their career path. In the interest of attracting altruistically motivated persons to the dental profession, we conclude that all dental schools that do not already supplement academic evaluation of applicants with methods to evaluate their motivations (by, for example, an interview or written essay) should consider adding those methods to their admissions criteria.

\section{Acknowledgments}

The authors would like to thank and acknowledge the following research coordinators: Insoon Chang (USA), Luka Kishida (Japan), Hoo Swee Tiang (Singapore), Kuan Lun Fu (Taiwan), Ercan Aga (Turkey), Alessandro Theunissen (Italy), Sunny Talathi (Russia), Worakanya Buranaphatthana (Thailand), and Kirpal Benawara (UK). 


\section{REFERENCES}

1. Petersen PE. Global policy for improvement of oral health in the 21st century: implications for oral health research of World Health Assembly 2007, World Health Organization. Community Dent Oral Epidemiol 2009;37(1):1-8.

2. Petersen PE. World Health Organization global policy for improvement of oral health: World Health Assembly 2007. Int Dent J 2008;58(3):115-21.

3. Aggarwal A, Mehta S, Gupta D, et al. Dental students' motivations and perceptions of a dental professional career in India. J Dent Educ 2012;76(11):1532-9.

4. Mashlah AM. Dentistry students' reasons for choosing dentistry as a career in Damascus University. East Mediterr Health J 2012;18(5):508-14.

5. Vahid Dastjerdi M, Mahdian M, Vahid Dastjerdi E, Namdari M. Study motives and career choices of Iranian medical and dental students. Acta Med Iran 2012;50(6):417-24.

6. Baharvand M, Moghaddam EJ, Pouretemad H, Alavi K. Attitudes of Iranian dental students toward their future careers: an exploratory study. J Dent Educ 2011;75(11):1489-95.

7. Freire M, Jordao M, de Paula Ferreira N, et al. Motivation towards career choice of Brazilian freshman students in a fifteen-year period. J Dent Educ 2011;75(1):115-21.

8. Karibe H, Suzuki A, Kawakami T, et al. Career choice and attitudes towards dental education amongst dental students in Japan and Sweden. Eur J Dent Educ 2009;13(2):80-6.

9. Lalloo R, Ayo-Yusuf O, Yengopal V. Early-phase dental students' motivations and expectations concerning the study and profession of dentistry. SADJ 2008;63(4): 216-20.

10. Hawley N, Ditmyer M, Sandoval V. Predental students' attitudes toward and perceptions of the dental profession. J Dent Educ 2008;72(12):1458-64.

11. Al-Bitar ZB, Sonbol HN, Al-Omari IK. Reasons for choosing dentistry as a career by Arab dental students. Eur J Dent Educ 2008;12(4):247-51.

12. Khami MR, Murtomaa H, Jafarian M, et al. Study motives and career choices of Iranian dental students. Med Princ Pract 2008;17(3):221-6.

13. Gallagher J, Clarke W, Wilson N. Understanding the motivation: a qualitative study of dental students' choice of professional career. Eur J Dent Educ 2008;12(2):89-98.

14. Karibe H, Suzuki A, Sekimoto T, et al. Cross-cultural comparison of the attitudes of dental students in three countries. J Dent Educ 2007;71(11):1457-66.

15. Orenuga OO, da Costa OO. Characteristics and study motivation of clinical dental students in Nigerian universities. J Dent Educ 2006;70(9):996-1003.

16. Scarbecz M, Ross JA. Gender differences in first-year dental students' motivation to attend dental school. J Dent Educ 2002;66(8):952-61.

17. Crossley ML, Mubarik A. A comparative investigation of dental and medical students' motivation towards career choice. Br Dent J 2002;193(8):471-3.
18. Maatouk F, El-May W, Ghedira H, Fathallah N. Profile of first-year dental students in Tunisia. East Mediterr Health J 2001;7(1-2):52-9.

19. Hallissey J, Hannigan A, Ray N. Reasons for choosing dentistry as a career: a survey of dental students attending a dental school in Ireland during 1998-99. Eur J Dent Educ 2000;4(2):77-81.

20. Brand AA, Chikte UM. Choosing dentistry as a careerpart I: a comparison of student motives. J Dent Assoc S Afr 1992;47(11):469-73.

21. Brand AA, Chikte UM. Choosing dentistry as a careerpart II: the meaning of motives. J Dent Assoc S Afr 1992;47(12):509-12.

22. Brand AA, Chikte UM, Thomas CJ. Choosing dentistry as a career: a profile of entering students (1992) to the University of Sydney, Australia. Aust Dent J 1996;41(3): 198-205.

23. Bernabé E, Icaza JL, Delgado-Angulo EK. Reasons for choosing dentistry as a career: a study involving male and female first-year students in Peru. Eur J Dent Educ 2006;10(4):236-41.

24. Newton P, Cabot L, Wilson N, Gallagher JE. The graduate entry generation: a qualitative study exploring the factors influencing the career expectations and aspirations of a graduating cohort of graduate entry dental students in one London institution. BMC Oral Health 2011;11:25.

25. Dalton D, Ortegren M. Gender differences in ethics research: the importance of controlling for the social desirability response bias. J Business Ethics 2011;103:73-93.

26. Chikte UM, Gilbert L, Brand AA, Lewis HA. Racial classification in dental literature: is it always necessary? J Dent Assoc S Afr 1989;44(8):337-9.

27. Fitzgerald JE, Tang SW, Ravindra P, Maxwell-Armstrong CA. Gender-related perceptions of careers in surgery among new medical graduates: results of a cross-sectional study. Am J Surg 2012;14.

28. Goldacre MJ, Davidson JM, Lambert TW. Doctors' age at domestic partnership and parenthood: cohort studies. J R Soc Med 2012;105(9):390-9.

29. The Geneva Hippocratic Oath. J Natl Med Assoc 1949;41(5):225-6.

30. Milton CL. Altruism. Nurs Sci Q 2012;25(3):222-4.

31. United States Bureau of Labor Statistics. Occupational outlook handbook: dentists. At: www.bls.gov/ooh/healthcare/dentists.htm. Accessed: November 28, 2012.

32. Government of Canada. Job futures: dentists. At: www. servicecanada.gc.ca/eng/qc/job futures/statistics/3113. shtml. Accessed: November 28, 2012.

33. Université Laval. Breakdown of average annual employment by economic activity: Russian Federation. At: www.arcticstat.org/Table.aspx/Region/Russian Federation/Indicator/\%5BLabor_Force\%5DIndustry! Agent/2008-08-20-22/10856. Accessed: November 30, 2012. 